4-2011

\title{
Mold and Alternaria Skin Test Reactivity and Asthma in Children in Connecticut
}

\author{
Todd W. Lyons \\ University of Connecticut School of Medicine and Dentistry \\ Dorothy B. Wakefield \\ University of Connecticut School of Medicine and Dentistry \\ Michelle M. Cloutier \\ University of Connecticut School of Medicine and Dentistry
}

Follow this and additional works at: https://opencommons.uconn.edu/uchcres_articles Part of the Medicine and Health Sciences Commons

\section{Recommended Citation}

Lyons, Todd W.; Wakefield, Dorothy B.; and Cloutier, Michelle M., "Mold and Alternaria Skin Test Reactivity and Asthma in Children in Connecticut" (2011). UCHC Articles - Research. 199.

https://opencommons.uconn.edu/uchcres_articles/199 
Published in final edited form as:

Ann Allergy Asthma Immunol. 2011 April ; 106(4): 301-307. doi:10.1016/j.anai.2010.12.009.

\title{
Mold and Alternaria skin test reactivity and asthma in children in Connecticut
}

\author{
Todd W. Lyons, MD ${ }^{\star}$, Dorothy B. Wakefield, MS ${ }^{\dagger, \ddagger}$, and Michelle M. Cloutier, MD ${ }^{\dagger, \ddagger}$ \\ *University of Connecticut School of Medicine, Farmington, Connecticut \\ ${ }^{\dagger}$ Asthma Center, Connecticut Children's Medical Center, Hartford, Connecticut \\ ‡Department of Pediatrics, University of Connecticut Health Center, Farmington, Connecticut
}

\section{Abstract}

\begin{abstract}
Background-Sensitivity to mold has been associated with asthma incidence, persistence, and severity.
\end{abstract}

\begin{abstract}
Objective-To examine the relationship between skin test reactivity (STR) to molds and specifically to Alternaria and asthma severity in a group of ethnically diverse children in Connecticut.
\end{abstract}

\begin{abstract}
Methods-Demographics and STR to 14 local allergens, including Alternaria, Penicillium, and mold mix, were obtained for 914 Puerto Rican, African American, and non-Hispanic white children.
\end{abstract}

\begin{abstract}
Results-A total of 126 children (14\%) had a positive skin test result to mold, and 58 (6\%) demonstrated STR to Alternaria. Compared with non-Hispanic white children, there was no difference in the likelihood of being sensitized to Alternaria for Puerto Rican and African American children (odds ratio [OR], 0.7; 95\% confidence interval [CI], 0.3-1.5; and OR, 0.9; 95\% CI, 0.4-2.2; respectively). In an adjusted analysis, Alternaria STR was associated with severe, persistent asthma (OR, 3.4; 95\% CI, 1.2-8.6) but did not predict increasing asthma severity. STR to cat (OR, 2.5; 95\% CI, 1.3-4.9) and $\operatorname{dog}(\mathrm{OR}, 2.9 ; 95 \% \mathrm{CI}, 1.3-6.0)$ was also associated with severe persistent asthma. Alternaria STR was associated with severe persistent asthma independent of the total number of positive skin test results.
\end{abstract}

Conclusions-Mold and Alternaria STR were uncommon among children in Connecticut. Alternaria STR was not associated with increasing asthma severity but was associated with severe, persistent asthma independent of the total number of positive skin test results. There was no association between ethnicity and Alternaria STR.

\section{INTRODUCTION}

Asthma is a significant cause of morbidity and mortality for an estimated 9 million children in the United States. ${ }^{1,2}$ The relationship between allergy and asthma in children is well established. ${ }^{3-6}$ Among children with asthma, the rate of skin test reactivity (STR) to one or more allergens has been reported to be as high as $80 \% .^{7}$ One allergen with emerging interest in its relationship to asthma is the spore-forming saprophyte Alternaria alternata. STR to

(C) 2011 American College of Allergy, Asthma \& Immunology.

Requests for reprints should be addressed to: Michelle M. Cloutier, MD, Asthma Center, Connecticut Children's Medical Center, 282 Washington St, Hartford, CT 06106, mclouti@ccmckids.org.

Dr Lyons is currently with Children's Hospital Boston and Boston Medical Center, Boston, Massachusetts.

Disclosures: Authors have nothing to disclose. 
Alternaria has been associated with both the development and persistence of asthma symptoms. ${ }^{3,7-14}$ Alternaria STR has also been associated with greater asthma severity, acute asthma exacerbations, and hospital and intensive care unit (ICU) admissions for asthma in adults and children, ${ }^{9,15-20}$ an observation possibly linked to the Alternaria-induced heightened airway responsiveness reported in children..$^{9,21,22}$

The relationship between Alternaria STR and ethnicity in children with asthma is incompletely understood. An increased prevalence of Alternaria STR in children of Hispanic and African American ethnicities has been reported. ${ }^{21}$ This result is consistent with increased prevalence of STR to other commonly tested allergens in minority children. ${ }^{21,23-27}$ In Connecticut, Puerto Rican and African American children have both increased STR to environmental allergens ${ }^{24}$ and greater asthma severity compared with nonHispanic white children. ${ }^{28-31}$

In this study, we examined the relationship among Alternaria STR, ethnicity, and asthma severity in a group of 914 ethnically diverse children in Connecticut. In addition, we investigated the relationship between Alternaria STR and pulmonary function in a subset of 56 children matched by age, sex, and ethnicity with and without Alternaria STR.

\section{METHODS}

\section{Study Population}

The study population included children with physician-diagnosed asthma who were referred for allergy skin testing (AST) between June 1, 1998, and December 1, 2007, as part of the previously described Easy Breathing Program. ${ }^{31,32}$ All children had current respiratory symptoms (defined as cough, wheezing, and/or shortness of breath within the previous 12 months). Asthma severity was classified by the child's physician as intermittent and mild, moderate, or severe persistent asthma using a validated set of questions ${ }^{33}$ following the guidelines of the National Asthma Education and Prevention Program. Surveys were completed by the parents of participants in Easy Breathing and included questions regarding demographics (age, ethnicity, sex, insurance), family history of asthma and allergic symptoms, environmental exposures (environmental tobacco smoke, pets, firewood, cockroaches, gas stoves, dust), and history of eczema. Ethnicity was self-reported and for this study is reported as non-Hispanic white, Puerto Rican, or African American.

Spirometry was performed in a subset of the study participants on referral from their physician. Children with STR to Alternaria were matched to other children without Alternaria STR on the basis of age, sex, ethnicity, asthma severity, and total number of positive allergen skin test results. Spirometry testing was conducted using the ndd EasyOne (Andover, Massachusetts) spirometer. All testing was performed by trained individuals and followed American Thoracic Society guidelines for quality and reproducibility. ${ }^{34}$ Spirometry was performed before and 15 to 20 minutes after inhalation of albuterol $(180 \mu \mathrm{g}$ with spacer). Predicted values for spirometric measures were determined using the Third National Health and Nutrition Examination Survey values. ${ }^{35}$

\section{Allergy Skin Testing}

AST was performed using the MultiTest device (Lincoln Diagnostics, Decatur, Illinois). Fourteen common, local allergens were tested, including mold mix (Alternaria, mixed Aspergillus, Cladosporium sphaerospermum, and mixed Penicillium), Penicillium, Alternaria, mixed tree pollen, dust mix, mixed grass pollen, mugwort/sage, ragweed, cockroach (Blattella germanica), dog dander, cat dander, mouse, house dust mite (Dermatophagoides pteronyssinus and Dermatophagoides farinae), and weed mix (AlkAbello, Round Rock, Texas). Histamine and saline solutions were used as positive and 
negative controls, respectively. A result for a specific allergen was considered positive if the maximum wheal diameter was at least $3 \mathrm{~mm}$ after subtraction of the negative control. In this study, the category of "any mold" includes children who tested positive to at least one of the individual or die mixed molds included in the AST panel.

\section{Statistical Analyses}

Univariate analyses among ordinal and nominal predictors and outcomes were performed using the Pearson $\chi^{2}$ tests. The Fisher exact test was used when cell sizes were small $(<5)$. The Student $t$ tests and analysis of variance analyses were used to assess relationships among continuous variables. Because some categories of data were sparse, we used exact logistic regression for multivariate models. ${ }^{36,37}$ This method computes the exact distributions of sufficient statistics for parameters of interest in a logistic regression model, conditional on the remaining parameters. The usual asymptotic methods often produce unreliable results when data are sparse or skewed. However, exact conditional inference produces valid results in these situations. Asthma severity was examined in 2 ways in multivariate models. First, severe persistent asthma was compared with asthma of all other severities. Exact multivariate logistic regression was used to model the relationship between the variables of interest and severe, persistent asthma (compared with all other severities), and exact odds ratios (ORs) with 95\% confidence intervals (CIs) were calculated. Second, all asthma severities were retained and cumulative logit models were used to examine whether allergen STR was predictive of increasing asthma severity. Paired $t$ tests were used to compare pulmonary function data in the subset of matched children. Statistical analyses were performed using JMP statistical software version 7.0 and SAS version 9.2 Statistical Software Package (SAS institute Inc. Cary, North Carolina).

\section{RESULTS}

\section{Characteristics of the Study Population}

Between June 1, 1998, and December 1, 2007, 1, 149 children with physician-confirmed asthma underwent AST, of whom 914 were younger than 18 years and Puerto Rican, African American, or non-Hispanic white (Fig 1). Of the 914 children, 66\% were Puerto Rican, 22\% were African American, and 12\% were non-Hispanic white (Table 1). Puerto Rican children referred for AST were older, more likely to have Medicaid insurance, and more likely to have a family history of asthma or allergic disease compared with African American or non-Hispanic white children. They were also less likely to have a personal history of eczema than African American children. To address the potential for these differences to affect later results, age, ethnicity, sex, and personal history of eczema were included in subsequent multivariate analyses. Seventy percent of referred children had persistent asthma. There was no difference in asthma severity among Puerto Rican, African American, and non-Hispanic white children who were referred for AST.

\section{Environmental Exposures}

Reported environmental exposures differed among the ethnic groups. Non-Hispanic white children were less likely than both Puerto Rican and African American children to report exposure to cockroach $(P<.001$ and $P<.001$, respectively) and gas stoves $(P<.001$ and $P$ $=.04$, respectively). They were also more likely than both Puerto Rican and African American children to report exposure to firewood $(P<.001$ and $P<.001$, respectively), cats $(P<.001$ and $P<.001$, respectively $)$, and $\operatorname{dogs}(P<.001$ and $P<.001$, respectively $)$. There was no difference in reported exposure to dust ( $P=.45$ and $P=.64$, respectively). Thirtyfour percent of study participants reported exposure to environmental tobacco smoke, with no difference among the ethnic groups $(P=.43)$. In univariate analyses, there was no association between STR to any of the molds in the AST panel and any of the environmental 
exposures studied. For this reason, none of these variables were included in subsequent multivariate analyses.

\section{AST Reactivity}

Sixty-nine percent of children with asthma demonstrated STR to one or more of the tested allergens (Table 1). Among the children with STR to at least one allergen, the mean (SD) number of positive skin test results was 3.6 (2.2). There was no difference in the mean number of positive skin test results among Puerto Rican, African American, and nonHispanic white children $(P=.27)$. However, fewer Puerto Rican children $(65 \%)$ had a positive skin test result to at least one allergen compared with African American (73\%) $(P$ $=.04)$ and non-Hispanic white children $(80 \%)(P=.002)$.

\section{Mold STR, Age, and Ethnicity}

A total of 126 study participants (14\%) had STR to one or more of the molds included in the AST panel (Table 1). In the univariate analysis (Table 2), there was no association between Alternaria STR and ethnicity. In contrast, non-Hispanic white children were more likely than Puerto Rican children to have STR to any mold and more likely than both Puerto Rican and African American children to have STR to mold mix. Non-Hispanic white children were also more likely to be sensitized to cat and less likely to be sensitized to cockroach than both African American and Puerto Rican children. Penicillium STR was more common among African American children than non-Hispanic white children $(P=.004)$. Dust mite sensitization was high in all ethnic groups, but there were no differences in rates of sensitization among Puerto Rican, African American, and non-Hispanic white children.

Children younger than 6 years were more likely to have STR to all of the molds than older children. In contrast, older children were more likely to have STR to cockroach and dust mite than children younger than 6 years (Table 2). Children 12 to 18 years of age were also more likely to have STR to dog. There were no significant differences in STR to cat by age.

\section{Mold STR and Asthma Severity}

In the univariate analysis, children with severe, persistent asthma were 3 times as likely to have STR to Alternaria, cat, and dog and twice as likely to have STR to cockroach compared with children with intermittent asthma (Table 2).

In multivariate models predicting increased asthma severity and controlling for age, ethnicity, and personal history of eczema, STR to molds was not predictive of increased asthma severity. In contrast, STR to cat $(P=.01), \operatorname{dog}(P=.02)$, and cockroach $(P=.04)$ was predictive of increased asthma severity. In other multivariate models that predicted severe persistent asthma compared with all other severities, however, STR to Alternaria, cat, and dog was highly associated with severe persistent asthma (Table 3 ). The total number of positive skin test results was not associated with either increasing severity $(P=.08)$ or severe persistent asthma $(P=.30)$.

In a final backward selection model that predicted severe persistent asthma compared with all other severities and contained STR to Alternaria, cat, and dog, and controlled for age, sex, ethnicity, and history of eczema, a positive allergen skin test result to cat (OR, 2.3; $95 \%$ CI, 1.2-4.2; $P=.009)$, Alternaria (OR, 2.6; 95\% CI, 1.1-6.4; $P=.04)$, and age older than 6 years $(P=.01)$ was predictive of severe persistent asthma, suggesting a contributing role for each of these factors in severe asthma. 


\section{Pulmonary Function Testing}

Spirometry was performed in 167 of the study participants, of whom 32 had a STR to Alternaria. Of these children with a positive skin test result to Alternaria, 28 were matched to 28 other children without Alternaria STR on the basis of age, sex, ethnicity, asthma severity, and total number of positive allergen skin test results (Table 4). There was no difference in pulmonary function test results for children with asthma and Alternaria STR compared with children with asthma without Alternaria STR when controlling for the number of positive AST results, asthma severity, age, sex, and ethnicity.

\section{DISCUSSION}

Alternaria alternata is one of the most common airborne fungi in outdoor and indoor environments. Considered an acroallergen, Alternaria spores are thought to be more antigenic than pollen because of their smaller size, their high levels, especially in late summer and after thunderstorms and high winds, and their ability (in mice) to produce potent $\mathrm{T}_{\mathrm{H}} 2$ adjuvant effects in the airway. ${ }^{38-40}$ In this ethnically diverse group of children with asthma who reside in New England, however, Alternaria STR was not common. The number of children with Alternaria STR did not vary by ethnicity or age. A positive skin test result to Alternaria was not associated with increasing asthma severity, although children with severe persistent asthma were more likely to have a positive skin test result to Alternaria compared with children with asthma of other severities. This is the first study, to our knowledge, to demonstrate an association between severe persistent asthma and a positive skin test result to Alternaria in a minority pediatric population and in a population that was not selected on the basis of medical services utilization and, in particular, ICU admission. In contrast, STR to cat, dog, and cockroach was associated with both increased asthma severity and severe persistent asthma. In a subset of children in whom pulmonary function testing was available, Alternaria STR was not associated with decreases in pulmonary function when children were matched for the number of positive AST results. The number of children with Alternaria STR and severe persistent asthma who underwent pulmonary function testing was small, and it is possible that such a relationship might have been missed.

Our low rate of Alternaria STR is in contrast to rates reported by others, ranging from 9.4\% to $46 \%$. $3,7,12,21-22,26,41-43$ Differences in study demographics and geographic location may explain these differences and have been demonstrated among inner-city children. ${ }^{21,42}$ In warm, dry climates, such as the semiarid climate in Arizona, Alternaria STR in children is very high, ${ }^{12}$ whereas considerably lower rates have been found in wet cool climates such as costal areas. ${ }^{9}$ Thus, the cool, wet New England climate that favors dust mite growth and subsequent sensitization may explain our low rates of Alternaria STR in children. Low rates of Alternaria STR have been reported in individuals with high rates of dust mite sensitization, as was observed in our study.

Our results suggest that Alternaria STR does not explain the previously reported ethnic differences in asthma severity, ${ }^{28-30}$ even though several population studies in adults have shown that sensitization to Alternaria is associated with an increase risk of having asthma and with severe episodes of asthma requiring admission to the ICU. An increased risk of sensitization to indoor and outdoor allergens in Puerto Rican and African American children with asthma has been demonstrated in other populations, and African American and Puerto Rican children in this study also demonstrated high rates of sensitization to indoor allergens, such as cockroach and dust mite but not to mold, $, 821,24$ suggesting that these are more important factors in these children. 
Ethnic differences in rates of Alternaria sensitization have been reported in the National Health and Nutrition Examination Study in which African American children, in contrast to Mexican American children, had higher odds of sensitivity to Alternaria than white children. No study, to our knowledge, has reported Alternaria STR rates in Puerto Rican children, although rates in Hispanics from South America and Mexican Americans were high. ${ }^{12,44}$

Despite the low overall rate of sensitization to Alternaria, results from this study demonstrate an association between severe, persistent asthma and Alternaria STR and are consistent with previous work in both adults ${ }^{16,18,20}$ and children. ${ }^{9,15}$ Thus, sensitization to Alternaria could be a marker for severe persistent asthma as defined by the National Asthma Education and Prevention Program ${ }^{45}$ and a risk factor for death or ICU admission. Alternatively, it may be a marker for increased atopy because sensitization to Alternaria seldom occurred alone but was often associated with multiple positive skin test results. In a multivariate model with both Alternaria and total number of positive skin test results, however, only Alternaria was predictive of severe persistent asthma.

There are several limitations to our study. The small number of positive Alternaria skin test results and the small number of children in whom spirometry testing was performed may have made it more difficult to detect potentially significant relationships. It is unlikely that differences in atopy alone explain this difference because the overall rate of atopy observed in our study participants is consistent with these other studies. More likely, the low prevalence of Alternaria STR in this study represents geographic or possibly ethnic differences in allergen sensitivity among our study population. ${ }^{42}$ Another limitation of our study is its cross-sectional design. This design allows us to determine associations among variables examined but not cause-and-effect relationships. In addition, a selection bias may exist in regard to children referred for AST. Our referral pattern, however, is consistent with the demographics of the greater Hartford, Connecticut region. Finally, many allergens, including Alternaria, show a seasonal pattern of distribution. ${ }^{10,46}$ It is possible that this seasonal distribution of Alternaria may have affected AST results.

In summary, STR to mold and Alternaria was not common among children in Connecticut. In this population, there was no association between ethnicity and Alternaria STR. STR to Alternaria was associated with severe persistent asthma in a multivariate analysis. Our data suggest that Alternaria STR is unlikely a major contributor to increasing asthma severity and ethnic differences in asthma severity in this population but may be a marker for children at risk for severe, persistent asthma.

\section{Acknowledgments}

Funding Sources: This work was supported by grant U18HS11147 from the Agency for Healthcare Research and Quality (Michelle M. Cloutier, principal investigator) and grant ROI HL68201-A101 from the National, Heart Lung and Blood Institute (A. David Paltiel, PhD, principal investigator).

We are grateful to the referring physicians who participate in Easy Breathing. We thank Charles B. Hall, $\mathrm{PhD}$ for review of the statistical methods, Autherene Grant for assistance with data management, Catherine Quirk and Gloria Jones for performing the allergy testing, and Barbara Turgeon for administrative support.

\section{References}

1. Dey AN, Bloom B. Summary health statistics for U.S. children: National Health Interview Survey, 2003. Vital Health Stat. 2005; 10(223):1-78.

2. Taylor WR, Newacheck PW. Impact of childhood asthma on health. Pediatrics. 1992; 90:657-662. [PubMed: 1408534] 
3. Arshad SH, Tariq SM, Matthews S, Hakim E. Sensitization to common allergens and its association with allergic disorders at age 4 years: a whole population birth cohort study. Pediatrics. 2001; 108:E33. [PubMed: 11483843]

4. Sears MR, Burrows B, Flannery EM, Herbison GP, Holdaway MD. Atopy in childhood, I: gender and allergen related risks for development of hay fever and asthma. Clin Exp Allergy. 1993; 23:941-948. [PubMed: 10779282]

5. Sears MR, Burrows B, Herbison GP, Flannery EM, Holdaway MD. Atopy in childhood. III: relationship with pulmonary function and airway responsiveness. Clin Exp Allergy. 1993; 23:957963. [PubMed: 10779284]

6. Squillace SP, Sporik RB, Rakes G, et al. Sensitization to dust mites as a dominant risk factor for asthma among adolescents living in central Virginia: multiple regression analysis of a populationbased study. Am J Respir Crit Care Med. 1997; 156:1760-1764. [PubMed: 9412552]

7. Akerman M, Valentine-Maher S, Rao M, et al. Allergen sensitivity and asthma severity at an inner city asthma center. J Asthma. 2003; 40:55-62. [PubMed: 12699212]

8. Arbes SJ Jr, Gergen PJ, Vaughn B, Zeldin DC. Asthma cases attributable to atopy: results from the Third National Health and Nutrition Examination Survey. J Allergy Clin Immunol. 2007; 120:1139-1145. [PubMed: 17889931]

9. Downs SH, Mitakakis TZ, Marks GB, et al. Clinical importance of Alternaria exposure in children. Am J Respir Crit Care Med. 2001; 164:455-459. [PubMed: 11500349]

10. Bush RK, Prochnau JJ. Alternaria-induced asthma. J Allergy Clin Immunol. 2004; 113:227-234. [PubMed: 14767434]

11. Etzel R, Rylander R. Indoor mold and Children's health. Environ Health Perspect. 1999; 107(suppl 3):463. [PubMed: 10346994]

12. Halonen M, Stern DA, Wright AL, Taussig LM, Martinez FD. Alternaria as a major allergen for asthma in children raised in a desert environment. Am J Respir Crit Care Med. 1997; 155:13561361. [PubMed: 9105079]

13. Lopez M, Salvaggio JE. Mold-sensitive asthma. Clin Rev Allergy. 1985; 3:183-196. [PubMed: 3986734]

14. Peat JK, Tovey E, Mellis CM, Leeder SR, Woolcock AJ. Importance of house dust mile and Alternaria allergens in childhood asthma: an epidemiological study in two climatic regions of Australia. Clin Exp Allergy. 1993; 23:812-820. [PubMed: 10780887]

15. Atkinson RW, Strachan DP, Anderson HR, Hajat S, Emberlin J. Temporal associations between daily counts of fungal spores and asthma exacerbations. Occup Environ Med. 2006; 63:580-590. [PubMed: 16551756]

16. Black PN, Udy AA, Brodie SM. Sensitivity to fungal allergens is a risk factor for life-threatening asthma. Allergy. 2000; 55:501-504. [PubMed: 10843433]

17. O’Driscoll BR, Hopkinson LC, Denning DW. Mold sensitization is, common amongst patients with severe asthma requiring multiple hospital admissions. BMC Pulm Med. 2005; 5:4. [PubMed: 15720706]

18. O'Hollaren MT, Yunginger JW, Offord KP, et al. Exposure to an aeroallergen as a possible precipitating factor in respiratory arrest in young patients with asthma. N Engl J Med. 1991; 324:359-363. [PubMed: 1987459]

19. Salo PM, Arbes SJ Jr, Sever M, et al. Exposure to Alternaria alternata, in US homes is associated with asthma symptoms. J Allergy Clin Immunol. 2006; 118:892-898. [PubMed: 17030243]

20. Zureik M, Neukirch C, Leynaert B, Liard R, Bousquet J, Neukirch F. Sensitisation to airborne moulds and severity of asthma: cross sectional study from European Community respiratory health survey. BMJ. 2002; 325:411-414. [PubMed: 12193354]

21. Lester LA, Rich SS, Blumenthal MN, et al. Ethnic differences in asthma and associated phenotypes: collaborative study on the genetics of asthma. J Allergy Clin Immunol. 2001; 108:357-362. [PubMed: 11544453]

22. Nelson HS, Szefler SJ, Jacobs J, Huss K, Shapiro G, Sternberg AL. The relationships among environmental allergen sensitization, allergen exposure, pulmonary function, and bronchial hyperresponsiveness in the Childhood Asthma Management Program. J Allergy Clin Immunol. 1999; 104 (4 pt 1):775-785. [PubMed: 10518821] 
23. Arbes SJ Jr, Gergen PJ, Elliott L, Zeldin DC. Prevalences of positive skin test responses to 10 common allergens in the US population: results from the third National Health and Nutrition Examination Survey. J Allergy Clin Immunol. 2005; 116:377-383. [PubMed: 16083793]

24. Celedon JC, Sredl D, Weiss ST, Pisarski M, Wakefield D, Cloutier M. Ethnicity and skin test reactivity to aeroallergens among asthmatic children in Connecticut. Chest. 2004; 125:85-92. [PubMed: 14718425]

25. Stevenson MD, Sellins S, Grube E, et al. Aeroallergen sensitization in healthy children: racial and socioeconomic correlates. J Pediatr. 2007; 151:187-191. [PubMed: 17643776]

26. Stevenson LA, Gergen PJ, Hoover DR, Rosenstreich D, Mannino DM, Matte TD. Sociodemographic correlates of indoor allergen sensitivity among United States children. J Allergy Clin Immunol. 2001; 108:747-752. [PubMed: 11692099]

27. Sarpong SB, Hamilton RG, Eggleston PA, Adkinson NF Jr. Socioeconomic status and race as risk factors for cockroach allergen exposure and sensitization in children with asthma. J Allergy Clin Immunol. 1996; 97:1393-1401. [PubMed: 8648037]

28. Cohen RT, Celedon JC, Hinckson VJ, et al. Health-care use among Puerto Rican and AfricanAmerican children with asthma. Chest. 2006; 130:463-471. [PubMed: 16899846]

29. Higgins PS, Wakefield D, Cloutier MM. Risk factors for asthma and asthma severity in nonurban children in Connecticut. Chest. 2005; 128:3846-3853. [PubMed: 16354853]

30. Ramsey CD, Celedon JC, Sredl DL, Weiss ST, Cloutier MM. Predictors of disease severity in children with asthma in Hartford, Connecticut. Pediatr Pulmonol. 2005; 39:268-275. [PubMed: 15668933]

31. Cloutier MM, Wakefield DB, Hall CB, Bailit HL. Childhood asthma in an urban community: prevalence, care system, and treatment. Chest. 2002; 122:1571-1579. [PubMed: 12426255]

32. Hall CB, Wakefield D, Rowe TM, Carlisle PS, Cloutier MM. Diagnosing pediatric asthma: validating the Easy Breathing Survey. J Pediatr. 2001; 139:267-272. [PubMed: 11487755]

33. Cowen MK, Wakefield DB, Cloutier MM. Classifying asthma severity: objective versus subjective measures. J Asthma. 2007; 44:711-715. [PubMed: 17994399]

34. Miller M, Hankinson J, Brusasco V, et al. Standardisation of spirometry. Eur Respir J. 2005; 26:319-338. [PubMed: 16055882]

35. Hankinson J, Odencrantz J, Fedan K. Spirometric reference values from a sample of the general U.S. population. Am J Respir Crit Care Med. 1999; 159:179-187. [PubMed: 9872837]

36. Cox, DR. The Analysis of Binary Data. New York, NY: Chapman \& Hall; 1970.

37. Hirji KF, Mehta CR, Patel MR. Computing distributions for exact logistic regression. J Am Stat Assoc. 1987; 82:1110-1117.

38. Pulimood TB, Corden JM, Bryden C, Sharpies L, Nasser SM. Epidemic asthma and the role of the fungal mold Alternaria alternata. J Allergy Clin Immunol. 2007; 120:610-617. [PubMed: 17624415]

39. Marks GY, Bush RK. It's blowing in the wind: new insights into thunderstorm-related asthma. J Allergy Clin Immunol. 2007; 120:530-532. [PubMed: 17765752]

40. Kobayashi T, Iijima K, Radhakrishnan S, et al. Asthma-related environmental fungus, Atternaria, activates dendritic cells and produces potent Th2 adjuvant activity. J Immunol. 2009; 182:25022510. [PubMed: 19201906]

41. Eggleston PA, Rosenstreich D, Lynn H, et al. Relationship of indoor allergen exposure to skin test sensitivity in inner-city children with asthma. J Allergy Clin Immunol. 1998; 102 (4 pt 1):563570. [PubMed: 9802363]

42. Gruchalla RS, Pongracic J, Plaul M, et al. Inner City Asthma Study: relationships among sensitivity, allergen exposure, and asthma morbidity. J Allergy Clin Immunol. 2005; 115:478-485. [PubMed: 15753892]

43. Kattan M, Mitchell H, Eggleston P, et al. Characteristics of inner-city children with asthma: the National Cooperative Inner-City Asthma Study. Pediatr Pulmonol. 1997; 24:253-262. [PubMed: 9368259]

44. Soto-Quiros M, Silverman EK, Hanson LA, Weiss ST, Celedon JC. Maternal history, sensitization to allergens, and current wheezing, rhinitis and eczema among children in Costa Rica. Pediatr Pulmonol. 2002; 33:237-243. [PubMed: 11921451] 
45. National Institutes of Health NH, Lung, and Blood Institute. Guidelines for the Diagnosis and Management of Asthma: Expert Panel Report 2: Update on Selected Topics 2002. Washington, DC: National Institutes of Health; 2002. p. 5074Publication 02

46. de Ana SG, Torres-Rodriguez JM, Ramirez EA, Garcia SM, Belmonte-Soler J. Seasonal distribution of Alternaria, Aspergillus, Cladosporium and Penicillium species isolated in homes of fungal allergic patients. J Investig Allergol Clin Immunol. 2006; 16:357-363. 


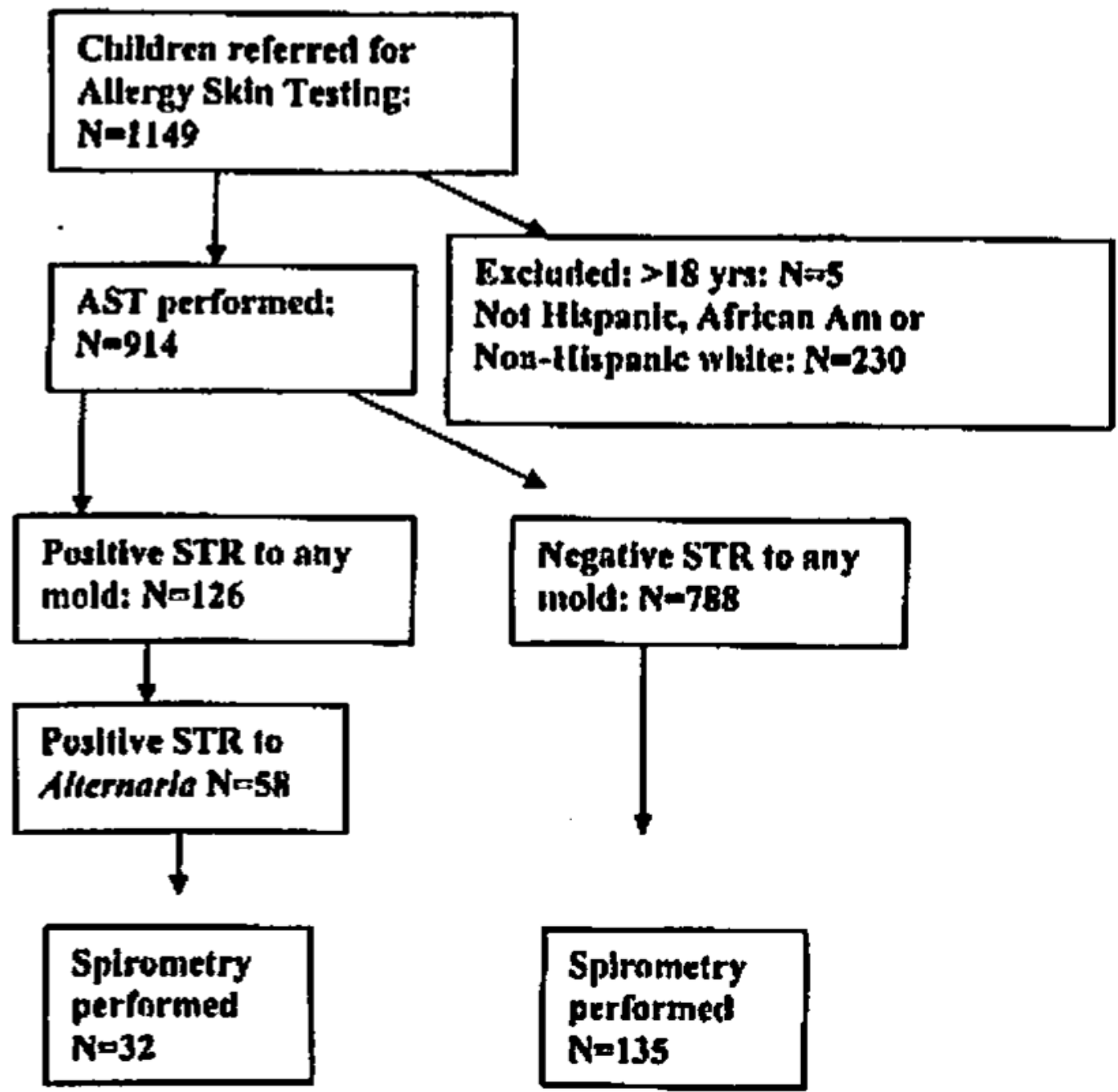

Figure 1.

Flow diagram of study population referred for allergy skin testing. 


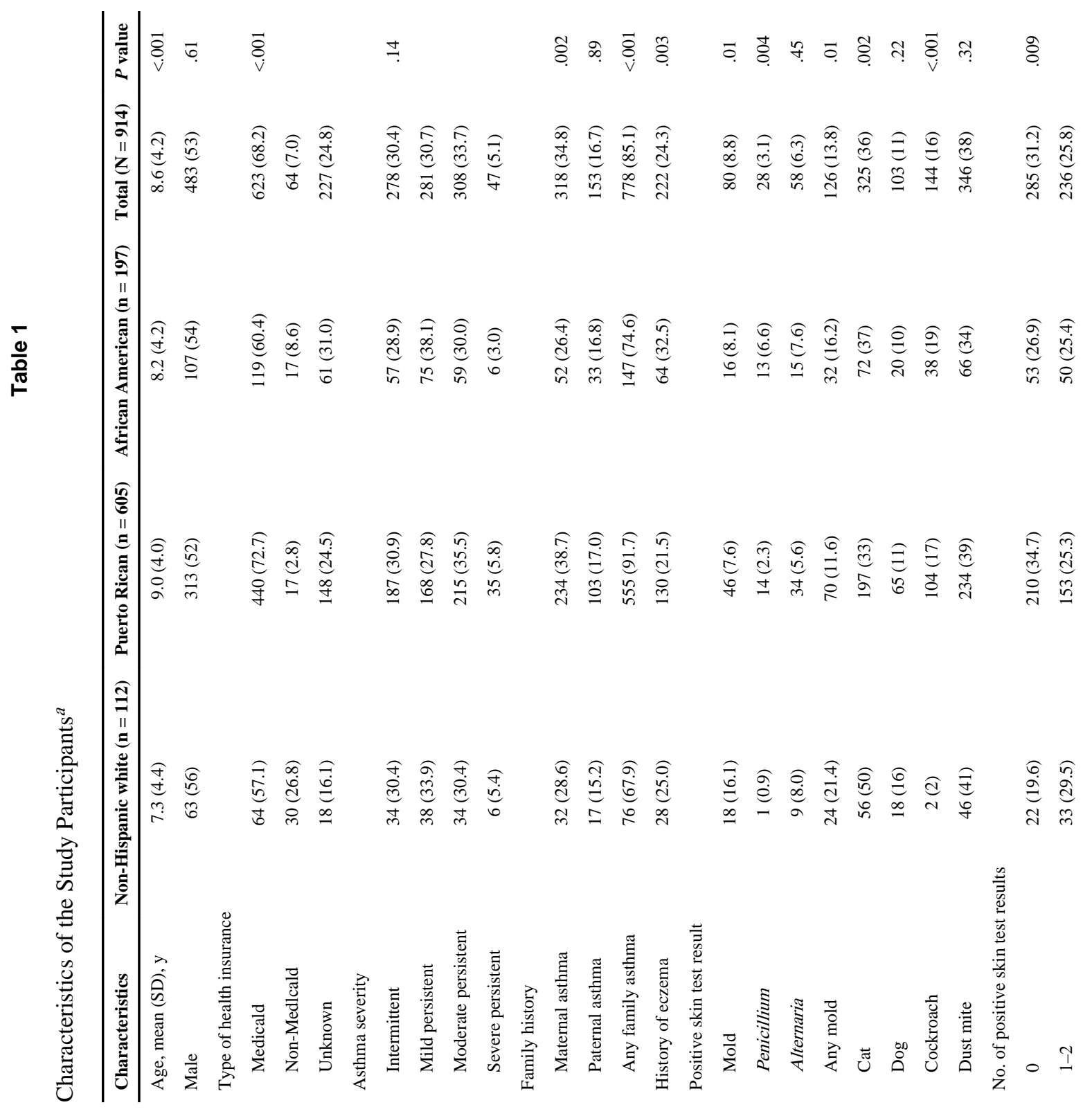




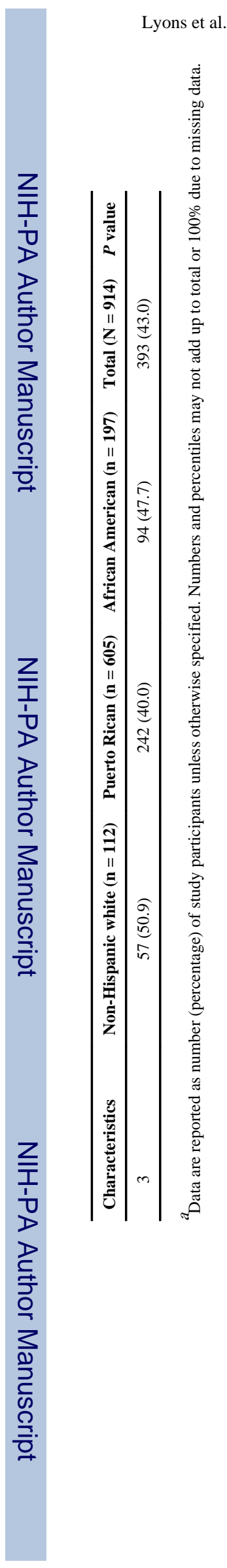

Page 12

Ann Allergy Asthma Immunol. Author manuscript; available in PMC 2013 July 15. 


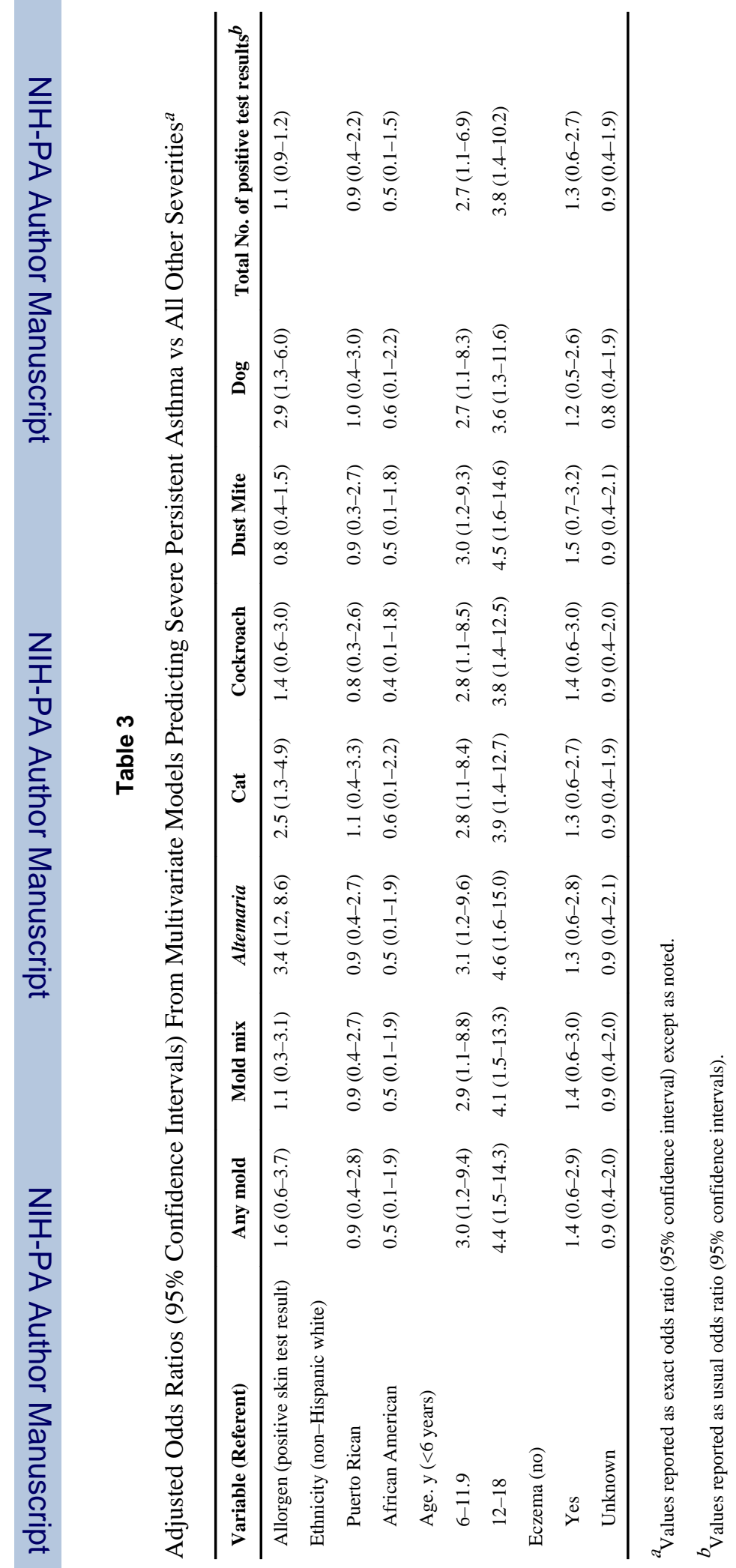

